\title{
Городской активизм молодёжи: практики и барьеры
}

Урбанистические исследования последних десятилетий затрагивают широкий спектр городских проблем, одной из которых выступает городской активизм молодёжи. Современное молодое поколение горожан отличает активная деятельная позиция, нацеленная на изменение городского пространства в соответствии со своими потребностями и запросами. Технократический подход к городу как системе взаимосвязанных объектов (зданий, сооружений, транспорта и пр.) уходит в прошлое. На смену ему приходит понимание, что город - живой организм, в котором действуют суб̆ъекты разного уровня и от которых зависит его дальнейшая судьба, его статус, его привлекательность.

Городское пространство, с одной стороны, выступает источником формирования новых запросов молодого поколения, но, с другой стороны, становится и условием реализации уже сформированных потребностей. Молодёжь, как отмечают Ю.А. Зубок и В.И. Чупров, "ориентируясь на традиционные и/или современные смыслы, ...приспосабливает меняющуюся реальность под свои потребности" [2, с. 81]. Город "задает" поведенческие практики молодежи и становится ареной ее самореализации и самовыражения, соответственно выступает социокультурной средой зарождения и воспроизводства социальных активностей.

Приспосабливая город "под себя" молодые горожане не только адаптируют его к своим интересам, но и трансформируют/изменяют, заявляя право на город в духе А. Лефевра [18]. Преобразуя город как условия реализации своих жизненных планов и намерений, молодёжь меняет и себя, приобретая новые социальные свойства и характеристики, новые роли и статусы. При этом "слияние" с городом становится формой интериоризации, способствуя становлению и развитию локально-территориальной идентичности. Речь идет о том, что, меняя город и изменяя себя, молодое поколение приобретает социальный опыт через освоение норм и ценностей, обретая социальную зрелость.

Городской активизм молодёжи представлен в различных ипостасях. При этом, как отмечает Н.Н. Седова, в "неполитических объединениях и сообществах россияне участвуют чаще, чем в организациях политической направленности" [13, с. 52]. В нашей работе под городским активизмом будем понимать добровольные публичные альтруистические неполитические индивидуальные и/или коллективные социальные действия молодёжи, выступающие условием реализации права на город и нацеленные на преобразование городского пространства.

Среди многообразия новых видов неполитического активизма выделяются DIY (сделай сам) практики, ЖКХ-арт, партизанинг, сквоттинг, зоозащита, вело-активизм и пр. Содержательно структурировать широкий репертуар молодёжных активностей не представляется возможным; некоторые из них уникальны и единичны, другие воспроизводятся на разных территориях, третьи - не закончены и открыты. Отсюда можно выделить ситуационный/ временный и постоянный/устойчивый активизм. Низовые инициативы могут идти как от конкретного индивида, так и от коллективного актора; могут быть

\author{
(C) Антонова Н. Л., Абрамова С. Б., 2021
} АНТОНОВА Наталья Леонидовна, д-р социол. наук, профессор кафедры прикладной социоло-
гии Уральского федерального университета (2. Eкатеринбург). E-mail: n-tata@mail.ru

АБРАМОВА Софья Борисовна, канд. социол. наук, доцент кафедры прикладной социологии Уральского федерального университета (2. Екатеринбург). E-mail: sofia_abramova@mail.ru

Исследование выполнено при финансовой поддержке РФФИ и Свердловской области в рамках научного проекта № 20-411-660012 p_a. 
созидательными и разрушительными; конструктивными и деструктивными; рациональными и иррациональными. Для новых городских активностей характерен преимущественно недрормальный характер организации, ориентация на практику малых дел, высокая чувствительность к вмешательству извне [12].

Французский исследователь М. де Серто отмечает, что в стратегиях городского планирования и управления повседневные инициативы и практики горожан, как правило, не предусмотрены [14]. При этом молодые горожане объединяются в группы, создают движения, мобилизуя ресурсы, для продвижения идей и проектов, нацеленных на улучшение пространства города. По мнению C.M. Москалевой и Е.В. Тыкановой, "несмотря на свой легитимный, а порой и легальный статус, такие общественные объединения сталкиваются с проблемами, связанными с отсутствием возможностей для диалога с чиновниками и представителями бизнеса и выработки совместных решений" [8, c. 105]. Возникают административные барьеры, которые приходится преодолевать городским активистам в попытках реализации права на город.

В этой связи важно понимать, что молодое поколение горожан как субъект социальной активности "становится базовым ресурсом интеллектуального, инновационного развития конкретного региона" [1, с. 26], ее особое "предназначение" выступать пионерами общественных преобразований [5, с. 17].

Интенсификация взаимодействия молодёжи с администрациями территорий, развитие диалога в системе взаимодействия с представителями властных структур, совершенствование коммуникативных механизмов и управленческих процедур в процессе развития городского пространства становятся условиями привлекательности города, точкой притяжения молодых инициативных людей, стремящихся, используя солидаризированные практики, изменить город.

Наше эмпирико-социологическое исследование было проведено в конце 2020 г. Объектом исследования стала молодёжь города Екатеринбурга. Всего методом онлайн-опроса (квотный вид отбора) было опрошено 800 респондентов в возрасте от 18 до 30 лет; из них: 60\% - девушки, 40\% -юноши. Распределение опрошенных по возрасту выглядит следующим образом: до 22 лет - 55,6\%, 23-26 лет - 27,8\%, старше 27 лет - 16,6\%. Учащаяся молодёжь составляет 50,3\%, работающая - 43,6\%, не работающая и не учащаяся $-6,1 \%$. Каждый пятый опрошенный состоит в браке. $35 \%$ респондентов идентифиицируют себя как представителей среднего класса. Обработка полученных результатов была проведена с использованием программы SPSS (версия 20).

Материалы исследования показали: городская молодёжь испытывает чувство ответственности, прежде всего, за то, что происходит в собственном дворе и/или доме $(59,7 \%)$, т.е. речь идет об ориентации молодого поколения на локальные практики преобразования пространства "вокруг себя". Что касается города в целом, то 36,8\% молодых екатеринбуржцев включают в зону своей ответственности социальные процессы, происходящие в полуторамиллионном городе.

Е.Л. Омельченко, рассматривая понятие социальной/гражданской активности, отмечает, что оно связано с желанием "участвовать, включаться в общественные преобразования, как потребность найти свое место, определить направленность жизни, обрести идентичность" [9, с. 66]. Результаты нашего исследования свидетельствуют, что молодое поколение дает невысокую оценку степени своего влияния на развитие города/двора/дома: 14,5\% респондентов полагают, что выступают субъектами изменений городской среды; $35,4 \%$ - субъектами "дворовых" инноваций. Такое положение связано, скорее, с традиционным подходом, реализуемым властными структурами в процессе управления городом (Urban policy), для которого горожанин - это, прежде всего, потребитель, а не инициатор/производитель городского пространства. Запросы и потребности горожан не часто являются предметом исследований и анализа городских администраций.

При этом 44,3\% молодых людей называют себя активными и инициативными горожанами, готовыми к преобразовательным действиям и партисипации в производство городского пространства. 85,2\% респондентов считают, что участие в деятельности общественных организаций и других некоммерческих негосударственных структур является наиболее успешным и эфрфектив- 
ным способом влияния на происходящие в городе процессы. $36,1 \%$ опрошенных готовы разместить информацию в социальных сетях, мессенджерах для мобилизации молодёжи и активизации ее действий, 31,9\% молодых горожан рассчитывают на свое мастерство убеждения друзей/знакомых/коллег в ситуациях, когда требуется решение вопросов, касающихся развития города.

От каких субъектов, по мнению молодёжи, зависит развитие города? Лидирующие позиции в качестве субъектов городских преобразований занимают представители органов власти: федеральных $(41,5 \%)$, региональных $(75,1 \%)$, местных/муниципальных $(67,8 \%)$. Горожан как инициатора изменений городской среды отмечает лишь каждый третий опрошенный. При этом 71,6\% молодых людей готовы к коллективному поведению, включению в новые социальные движения, направленные на улучшение качества жизни в условиях города.

Среди основных причин, снижающих проявление активности в решении городских проблем, молодёжь отмечает: отсутствие веры в возможность позитивных изменений (61,6\%), дефицит информации о механизмах/инструментах влияния на ситуацию в городе (50,6\%), страх перед санкциями, которые могут последовать за проявление активностей (40\%).

Тем не менее за последний год каждый пятый опрошенный $(22,2 \%)$ использовал сеть интернет как площадку выражения/демонстрации своей позиции. В исследовании Фонда общественного мнения, проведенном в 2017 г., утверждается, что около трети молодежи публично высказываются по новостными поводам в интернете [15]. И.Б. Плешкевич отмечает, что активность - это не только воплощение каких-либо идей, но и выражение собственного мнения (опросы, голосования и т.п.), появляются новые онлайн-фрормы социальной активности [10, с. 47]. Материалы опроса Всероссийского центра общественного мнения показывают, что молодёжь (по сравнению с другими возрастными группами) максимально вовлечена в виртуальное пространство: 91\% молодых людей от 18 до 24 лет почти ежедневно пользуются социальными сетями [3]. Эти данные убедительно заявляют возможности новых медиа в становлении и развитии городского молодёжного активизма. Обсуждение и создание общественного резонанса, призыв к реальным действиям способны стать источником коллективных форм поведенческих практик.

14,9\% респондентов в течение последнего года принимали участие в субботниках и иных мероприятиях по благоустройству города/двора/подъезда, $11,5 \%$ участвовали в собраниях жильцов дома, 11,4\% включились в деятельность общественных/негосударственных некоммерческих организаций. Что касается протестного поведения, то 8\% опрошенных проявили гражданскую активность через непосредственное участие в акциях протеста/митингах/пикетах, касающихся планирования и развития городской среды. Важным считаем подчеркнуть, что чуть более половины опрошенной городской молодёжи $(51,9 \%)$ оказалась пассивной, что связано, скорее, с ориентацией на индивидуализм и эгоизм, установлением четких границ между личным и общественным. Таким образом, в молодом поколении горожан заметно выделяется как активная часть, так и пассивная, при этом доли этих групп примерно равны.

Какие цели преследует молодёжь в целом, принимая решение об участии в жизни города? 58,4\% опрошенных апеллируют к желанию жить в чистом и опрятном городе, а 46,6\% стоят на идеалистических позициях, считая, что своими действиями изменяют мир к лучшему. Несомненно, чистоту городских улиц и дворов можно "отдать на откуп" коммунальным службам. Молодёжь, на наш взгляд, персонифицирует город, "очеловечивает" его, считая, что комфортность городского пространства складывается не только из транспортной инфраструктуры, безопасности, доступности услуг и т.п. Город начинается с человека, с его желания и стремления сделать комфортным своими силами. Практически каждый четвертый респондент $(23,1 \%)$ считает, что смог бы оказать посильное участие в охране окружающей среды. При этом третья часть респондентов $(34,0 \%)$ критикует городские власти за инертность в решении вопросов качественного преобразования городского пространства, в котором удовлетворялись бы потребности и интересы разных групп горожан.

Городским активистам в попытках преобразования городской среды приходится преодолевать различного рода барьеры. В ходе исследования опрошенная молодёжь отметила, что такими барьерами являются, прежде 
всего, трудности взаимодействия с городской администрацией $(85,2 \%)$, столкновение с правоохранительными органами $(73,8 \%)$, а также конфликты с жителями города (43,9\%).

В системе взаимодействия с административными структурами, пожалуй, ключевым вопросом становится открытость/закрытость городской администрации к "низовым" инициативным проектам и мероприятиям. Судя по результатам опроса, в общественном сознании молодого поколения циркулирует представление о том, что политические элиты Екатеринбурга, скорее, негативно будут относиться к начинаниям/инновациям. В исследовании М.Н. Королевой и М.А. Черновой лидеры городских проектов Москвы и Томска указали на такие барьеры, как незаинтересованность чиновников в развитии города, дефицит информации о легальных инструментах реализации проектов, отсутствие выстроенных процессов взаимодействия, бюрократия, неэффективность инструментов обратной связи, зависимость эффективности управленческих структур города от конкретных людей и даже угроза нападения, фризической расправы при бездействии правоохранительных органов [4, с. 98].

Опасения и страхи, связанные с применением репрессий за несанкционированные активности, также отчасти свидетельствуют о невысокой степени отзывчивости городской администрации на молодёжные инициативы. Соответственно, необходимы союзники в административных структурах, способные лоббировать интересы городских активистов [16]. Проблема опасений респондентов, касающихся возможных столкновений с правоохранительными органами, на наш взгляд, также связана и с информационной ловушкой. С одной стороны, молодое поколение - это поколение активных Интернет-пользователей: молодежь черпает информацию из социальных сетей, сайтов и т.п. С другой стороны, информационный мусор ("страшилки", фрейки и т.п.) мешает молодому поколению распознать институционально закрепленные техники, процедуры, инструменты реализации активности в условиях города, двора, подъезда. Например, будут ли санкции, если поставить скамейку возле детской площадки во дворе дома? Соответственно, незнание формализованных механизмов подобного рода действий вкупе с вымышленными "историями" о мерах воздействия со стороны правоохранительных органов за подобную активность и становится барьером в преобразовании города/района/двора.

Что касается возникновения возможных конфликтных ситуаций с жителями города, то отметим, что в современной урбанистике актуализируется понятие Nimby (not in my back yard), которое было введено в 1980 г. Эмили Травел Ливези и популяризировано британским политиком Николасом Ридли из Консервативной партии [11]. "Не на моем заднем дворе" - именно данное положение характеризует нимбистов, оказывающих сопротивление изменениям общественных городских пространств. При этом их не останавливает высокая социальная значимость проектов, они даже готовы их поддержать, но исключительно за пределами места своего проживания. Традиционно, характеризуя группу нимбистов, исследователи рассматривают ее сквозь призму протестных действий, направленных на борьбу с размещением объектов, оказывающих неблагоприятное воздействие на экологию (мусороперерабатывающие заводы и т.п.), психо-эмощиональное состояние людей (психиатрические клиники, тюрьмы) [17; 19].

Сегодня мы наблюдаем, что нимбизм как социальное явление расширяется: активная часть горожан отстаивает публичные городские пространства (например, защита сквера у театра драмы в г. Екатеринбург), сопротивляется точечной застройке, стремится сохранить памятники архитектуры. Однако молодое поколение - участники опроса, высказывают опасения, что локально-территориальная активизм может оказаться не понятым/не принятым некоторыми группами горожан. Так, например, ЖКХ-арт как DIY - практика (Do It Yourself - сделай сам) неоднозначно оценивается представителями разных поколений [7]. Молодёжь негативно относится к "поделкам" старшего поколения и, соответственно, высказывает опасения, что ее инициативы также могут вызвать негативные оценки у других жителей города. Как справедливо отмечают Е.С. Кочухова и В.С. Мартьянов: "в каждом конкретном случае поиск собственной модели развития города потребует выявления и последующего компромисса всех значимых интересов" [6, с. 57]. 
Материалы исследования позволили прийти к следующим выводам. Молодёжь крупного промышленного центра претендует на статус актора городских преобразований, стремясь в своих инициативах реализовать право на город. Городской активизм имеет созидательный характер, масштабы которого определяются самостоятельным свободным выбором молодого горожанина. Участие молодого поколения в развитии городской среды свидетельствует о становлении гражданской культуры и субъектности, формирует чувство ответственности за город, поддерживает локально-территориальную идентичность.

Результаты опроса показали, что, прежде всего, молодёжь ориентируется в своих практиках на улучшение территории, ограниченной местом проживания, "перекраивая" двор/дом/подъезд под свои потребности и запросы, при этом используя солидаризированное коллективное поведения, объединяясь с другими заинтересованными участниками на основе общности мировоззрения и активистско-деятельностных стратегий. Активность молодёжи имеет неполитический характер и проявляется в практиках благоустройства, создания комфортной среды для проживания.

Вместе с этим, как показало исследование, существуют барьеры реализации идей и проектов, среди которых - отсутствие возможностей в принятии административных решений о состоянии и перспективах развития города, а также опасения, что городская администрация не примет участия в диалоге. Соответственно, важным становится разработка инструментов интеграции городских активистов и действующих властных структур, нацеленных на рассмотрение "низовых" инициатив и партисипации молодых горожан в планирование и производство города.

Мы полагаем, что одним из действенных механизмов включения молодого поколения в процессы городского развития могут стать образовательные проекты и мероприятия, разработанные совместно с образовательными организациями, учреждениями культуры и муниципальными структурами и направленные на демонстрацию институционализированных практик преобразования пространства города. Важным видится и привлечение новых медиа для тиражирования позитивного опыта городских активистов, что будет способствовать формированию практико-ориентированных моделей преобразовательной деятельности молодёжи. В этом ключе представляется перспективным разработка конкретных рекомендаций в форме дорожных карт/ маршрутов, в которых прописывается последовательность действий для реализации типичных видов, прежде всего, "дворовых" активностей.

\section{Литература}

1. Антонова Н.Л., Абрамова С.Б., Пименова О.И. Образ "города для жизни" в представлениях студентов Екатеринбурга // Вестник Тюменского государственного университета. Социально-экономические и правовые исследования. 2018. Т. 4. № 2. C. 23-37. DOI: $10.21684 / 2411-7897-2018-4-2-23-37$.

2. Зубок Ю.А., Чупров В.И. Саморегуляция смысложизненных ценностей в культурном пространстве молодёжи // Вестник Института социологии. 2019. Т. 10. № 4. C. 164-186. DOI: 10.19181/vis.2019.31.4.614

3. Каждому возрасту - свои сети. Всероссийский центр изучения общественного мнения. [Электронный ресурc]. URL: https:// wciom.ru/analytical-reviews/analiticheskiiobzor/kazhdomu-vozrastu-svoi-seti (дата обращения: 05.01.2020).

4. Королева М.Н., Чернова М.А. Городской активизм: управленческие практики как ресурс и барьер развития городских проектов // Сощиологические исследования. 2018. № 9. С. 93-101. DOI: $10.31857 /$ S013216250001963-2.

5. Костина Е. Ю., Орлова Н. А. Социальная мобильность в приграничье: взгляд молодежи // Ойкумена. Регионоведческие исследования. 2020. № 4. С. 16-22. DOI: 10.24866/1998-6785/2020-4/16-22

6. Кочухова Е.С., Мартьянов В.С. Креативный город или право на город: альтернативы урбанистического развития в российском контексте // Антиномии. 2019. Т.19. № 2 . C. 45-66.

7. Кудряшов И. "Колорит": Примитив и творчество. Народный дадаизм ЖЭК-арта. [Электронный ресурс]. URL: https:// concepture.club/post/rubrika_2021/zhek-art-aspublic-dadaism (дата обращения: 15.01.2020). 
8. Москалева C.M., Тыканова Е.В. Социальные условия деятельности гражданских и экспертных групп по улучшению качества городской среды // Журнал социологии и сощиальной антропологии. 2016. Т. 19. № 4. С. 103-120.

9. Омельченко Е.Л. Молодежный активизм в России и глобальные трансформации его смысла // Журнал исследований социальной политики. 2005. Т. 3. № 1. С. 5986.

10. Плешкевич И.Б. Типология участия граждан в развитии городского пространства // Вестник Удмуртского университета. Сощиология. Политология. Международные отношения. 2020. Т. 4. Вып. 1. С. 43-50. DOI: 10.35634/2587-9030-2020-4-1-43-50

11. Пономарева A.M. 2019.02.017. Габович М. Опасны ли копикэт-практики?"Стратегия-31", "Русская пробежка", "Бессмертный полк" и трансформативный потенциал неиерархических движений. Gabowitsch M. are copycats subversive? Strategy-31, the Russian runs, the immortal regiment and the transformative potential of non-hierarchical movements // Problems of Post-Communism. N.Y. 2016. Nov. 29. P. 1-18 // Социальные и гуманитарные науки. Отечественная и зарубежная литература. Серия 11: Социология. 2019. № 2. С. 108-117. [Электронный ресурс]. URL: https:// cyberleninka.ru/article/ n/2019-02-017-gabovich-m-opasny-li-kopiket-praktiki-strategiya-31-russkaya-probezhkabessmertnyy-polk-i-transformativnyy-potentsial (дата обращения: 11.01.2020).

12. Российский неполитический активизм: наброски к портрету героя. Отчет о результатах исследования активизма в России. Пермь: Центр гражданского анализа и независимых исследований "ГРАНИ", 2014. [Электронный ресурс]. URL: http:// old. president-sovet.ru/structure/group_detst/materials/неполитический\%20активизм.pdf (дата обращения: 10.01.2020).

13. Седова Н.Н. Гражданский активизм в современной России: форматы, фракторы, социальная база // Социологический журнал. 2014. № 2. С. 48-71.

14. Серто М. де. Изобретение повседневности. Искусство делать / пер. с фрр. Д. Калугина, Н. Мовниной. СПб.: Изд-во Европейского университета в Санкт-Петербурге, 2013. $330 \mathrm{c}$

15. Социальная и политическая активность молодежи. Фонд Общественное Мнение. [Электронный ресурс]. URL: https:// fom.ru/TSennosti/13286 (дата обращения: 11.01.2020).

16. Gotham K.F. Political opportunity, community identity, and the emergence of a local anti-expressway movement // Social Problems. 1999. № 46(3). P. 332-54. DOI: $10.2307 / 3097104$.

17. Halstead J.M., Luloff A.E., Myers S.D. An examination of the NIMBY syndrome: Why not in my backyard? // Journal of the Community Development Society. 1993. № 24(1). P. 88-102. DOI: 10.1080/15575339309489921. $260 \mathrm{p}$

18. Lefebvre H. Writings on Cities. Cambridge, MA: Blackwell Publishers, 1996.

19. Terwel B.W., Daamen D.D.L., Mors E. ter. Not in My Back Yard (NIMBY) Sentiments and the Structure of Initial Local Attitudes Toward CO2 Storage Plans // Energy Procedia. 2013. № 37. P. 7462-7463. DOI: 10.1016/j.egypro.2013.06.689.

\section{Транслитерация по ГОСТ 7.79-2000 система Б}

1. Antonova N.L., Abramova S.B., Pimenova O.I. Obraz "goroda dlya zhizni" v predstavleniyakh studentov Ekaterinburga // Vestnik Tyumenskogo gosudarstvennogo universiteta. Sotsial'no-ehkonomicheskie i pravovye issledovaniya. 2018. T. 4. № 2. S. $23-37$. DOI: 10.21684/2411-7897-2018-4-2-23-37.

2. Zubok YU.A., CHuprov V.I. Samoregulyatsiya smyslozhiznennykh tsennostej v kul'turnom prostranstve molodyozhi // Vestnik Instituta sotsiologii. 2019. T. 10. № 4. S. 164-186. DOI: 10.19181/vis.2019.31.4.614

3. Kazhdomu vozrastu - svoi seti. Vserossijskij tsentr izucheniya obshhestvennogo mneniya. [Ehlektronnyj resurs]. URL: https:// wciom.ru/analytical-reviews/analiticheskii-obzor/kazhdomu-vozrastu-svoi-seti (data obrashheniya: 05.01.2020).

4. Koroleva M.N., CHernova M.A. Gorodskoj aktivizm: upravlencheskie praktiki kak resurs i bar'er razvitiya gorodskikh proektov // Sotsiologicheskie issledovaniya. 2018. № 9. S. 93-101.

5. DOI: 10.31857/S013216250001963-2.

6. Kostina E. YU., Orlova N. A. Sotsial'naya mobil'nost' v prigranich'e: vzglyad molodezhi // Ojkumena. Regionovedcheskie issledovaniya. 2020. № 4. S. 16-22. DOI: 10.24866/1998-6785/2020-4/16-22

7. Kochukhova E.S., Mart'yanov V.S. Kreativnyj gorod ili pravo na gorod: al'ternativy urbanisticheskogo razvitiya v rossijskom kontekste // Antinomii. 2019. T.19. № 2. S. 45-66.

8. Kudryashov I. "Kolorit": Primitiv i tvorchestvo. Narodnyj dadaizm ZHEHK-arta. [Ehlektronnyj resurs]. URL: https:// concepture.club/post/rubrika_2021/zhek-art-as-public-dadaism (data obrashheniya: 15.01.2020). 
9. Moskaleva S.M., Tykanova E.V. Sotsial'nye usloviya deyatel'nosti grazhdanskikh i ehkspertnykh grupp po uluchsheniyu kachestva gorodskoj sredy // ZHurnal sotsiologii i sotsial'noj antropologii. 2016. T. 19. № 4. S. 103-120.

10. Omel'chenko E.L. Molodezhnyj aktivizm v Rossii i global'nye transformatsii ego smysla // ZHurnal issledovanij sotsial'noj politiki. 2005. T. 3. № 1. S. 59-86.

11. Pleshkevich I.B. Tipologiya uchastiya grazhdan v razvitii gorodskogo prostranstva // Vestnik Udmurtskogo universiteta. Sotsiologiya. Politologiya. Mezhdunarodnye otnosheniya. 2020. T. 4. Vyp. 1. S. 43-50. DOI: 10.35634/2587-9030-2020-4-1-43-50

12. Ponomareva A.M. 2019.02.017. Gabovich M. Opasny li kopikeht-praktiki? "Strategiya-31", "Russkaya probezhka", "Bessmertnyj polk" i transformativnyj potentsial neierarkhicheskikh dvizhenij. Gabowitsch M. are sopycats subversive? Strategy-31, the Russian runs, the immortal regiment and the transformative potential of non-hierarchical movements // Problems of Post-Communism. N.Y. 2016. Nov. 29. P. 1-18// Sotsial'nye i gumanitarnye nauki. Otechestvennaya i zarubezhnaya literatura. Seriya 11: Sotsiologiya. 2019. № 2. S. 108-117. [Ehlektronnyj resurs]. URL: https:// cyberleninka.ru/article/n/201902-017-gabovich-m-opasny-li-kopiket-praktiki-strategiya-31-russkaya-probezhka-bessmertnyy-polk-i-transformativnyy-potentsial (data obrashheniya: 11.01.2020).

13. Rossijskij nepoliticheskij aktivizm: nabroski k portretu geroya. Otchet o rezul'tatakh issledovaniya aktivizma v Rossii. Perm': TSentr grazhdanskogo analiza i nezavisimykh issledovanij "GRANI", 2014. [Ehlektronnyj resurs]. URL: http:// old.president-sovet. ru/structure/group_detst/materials/nepoliticheskij\%20aktivizm.pdf (data obrashheniya: 10.01.2020).

14. Sedova N.N. Grazhdanskij aktivizm v sovremennoj Rossii: formaty, faktory, sotsial'naya baza // Sotsiologicheskij zhurnal. 2014. № 2. S. 48-71.

15. Serto M. de. Izobretenie povsednevnosti. Iskusstvo delat' / per. s fr. D. Kalugina, N. Movninoj. SPb.: Izd-vo Evropejskogo universiteta v Sankt-Peterburge, 2013. 330 s.

16. Sotsial'naya i politicheskaya aktivnost' molodezhi. Fond Obshhestvennoe Mnenie. [Ehlektronnyj resurs]. URL: https:// fom.ru/TSennosti/13286 (data obrashheniya: 11.01.2020).

17. Gotham K.F. Political opportunity, community identity, and the emergence of a local anti-expressway movement // Social Problems. 1999. № 46(3). P. 332-54. DOI: $10.2307 / 3097104$

18. Halstead J.M., Luloff A.E., Myers S.D. An examination of the NIMBY syndrome: Why not in my backyard? // Journal of the Community Development Society. 1993. № 24(1). P. 88-102. DOI: 10.1080/15575339309489921. $260 \mathrm{p}$

19. Lefebvre H. Writings on Cities. Cambridge, MA: Blackwell Publishers, 1996.

20. Terwel B.W., Daamen D.D.L., Mors E. ter. Not in My Back Yard (NIMBY) Sentiments and the Structure of Initial Local Attitudes Toward CO2 Storage Plans // Energy Procedia. 2013. № 37. P. 7462-7463. DOI: 10.1016/j.egypro.2013.06.689. 


\begin{abstract}
Антонова Н. Л., Абрамова С. Б. Городской активизм молодёжи: практики и барьеры.

В статье на основе материалов эмпирико-социологического исследования, проведенного в городе Екатеринбурге $(\mathrm{n}=800)$ раскрываются особенности городского активизма молодого поколения. Утверждается, что молодёжь, стремясь реализовать право на город, ориентируется на созидательные локальные практики, нацеленные на преобразование пространства "вокруг себя". Активность молодых горожан имеет неполитический солидаризированный характер, поведенческие практики касаются благоустройства и создания комфортной среды для проживания. Барьерами, препятствующими реализации идей и проектов, становятся трудности взаимодействия с административными структурами управления территорией, опасения, связанные с возможными санкциями за проявление низовых инициатив.
\end{abstract}

Ключевые слова: город, городской активизл, молодёжь, право на город, партисипация, практики, барьеры Barriers.

Antonova N. L., Abramova S. B. Urban Youth Activism: Practices and

The article reveals the features of urban activism of the younger generation based on the materials of an empirical-sociological study conducted in the city of Yekaterinburg ( $\mathrm{n}=800$ ). It is argued that young people, striving to realize their right to the city, are guided by the creative local practices aimed at transforming the space "around them". The activity of young townspeople has a non-political solidarized character, behavioral practices relate to the improvement and creation of a comfortable living environment. Difficulties in interacting with the administrative structures of territorial management, fears associated with possible sanctions for the manifestation of grassroots initiatives become barriers to the implementation of ideas and projects. barriers

Key words: city, urban activism, youth, the right to the city, participation, practices,

Для цитирования: Антонова Н. Л., Абрамова С. Б. Городской активизм молодёжи: практики и барьеры // Ойкумена. Регионоведческие исследования. 2021. № 2. С. 96-103. DOI: $10.24866 / 1998-6785 / 2021-2 / 96-103$

For citation: Antonova N. L., Abramova S. B. Urban Youth Activism: Practices and Barriers // Ojkumena. Regional researches. 2021. № 2. P. 96-103. DOI: 10.24866/1998-6785/2021-2/96103 